\title{
Aspectos parasitológicos y epidemiológicos de los donantes de sangre seropositivos para Trypanosoma cruzi, en un hospital universitario
}

\author{
Pablo Galaz ${ }^{1 a}$, Stephanie G arcíala, Rubén Mercado ${ }^{1 b}$, \\ Elsa O rrego 2c, Blanca Pagliero2c, María \\ del Carmen Contreras ${ }^{1 d}$, Patricia Salinas ${ }^{1 d}$, Carlos Arancibialc. \\ Parasitological and epidemiological \\ aspects of Trypanosoma cruzi \\ seropositive blood donors
}

Background: After the interruption of the transmission of Chagas disease via vector insects in Chile, there is little available epidemiological information about this parasitosis in blood banks. Aim: To update the rates of T cruzi positive blood donors. To measure parasitological and epidemiological parameters in blood donors with anti $\mathrm{T}$ cruzi antibodies. Material and Methods: An ELSA-T cruzi test was carried out in 30,309 blood donors between 2000 and 2004. In 75 blood donors with an ELSA-T cruzi positive test and 79 donors with negative EUSA (controls), a survey about personal or parental history of biting by a kissing bug (Triatomine), was performed. A blood sample was also obtained to perform Polymerase Chain Reaction (PCR) for T cruzi and a xenodiagnostic test. Results: Annual frequency of positive ELSA for T cruzi serum antibodies in blood donors varied from $0.31 \%$ to $0.45 \%$. Twenty eight percent of subjects with positive and $6 \%$ of subjects with negative specific antibodies answered the survey about biting. PCR and xenodiagnostic test were positive in 52 (69\%) and 16 (21\%) of positive ELISA-T cruzi test blood donors, respectively. Xenodiagnostic was also positive in 5 individuals who had a negative PCR. Conclusions: Seroprevalence of T cruzi antibodies decreased from 3\% in 1968 to 0.3\% in 2004 (Rev Méd Chile 2007; 135: 1291-5).

(Key words: Blood donors; Trypanosoma cruzi; Xenodiagnosis)

\footnotetext{
Recibido el 14 de noviembre, 2006. Aceptado el 19 de abril, 2007.

${ }^{1}$ Unidad Docente de Parasitología, Facultad de Medicina, Universidad de Chile. ${ }^{2}$ Banco de Sangre, Hospital Clínico Universidad de Chile.

aAyudante-Alumno de Parasitología, Estudiante de Medicina, Universidad de Chile

bPh.D. en Parasitología

CTecnólogo Médico

dQuímico Farmacéutico
}

Correspondencia a: Rubén Mercado. Unidad Docente de Parasitología, Facultad de Medicina, Universidad de Chile. Interior Parque Quinta Normal. Fono: 56-2-6817911. Fax: 56-2-6814499. E mail: rmercado@med.uchile.cl 
$\mathrm{E}_{\mathrm{la}}^{\mathrm{n}}$ Chile, en 1962, se describió por primera vez la frecuencia de donantes de sangre infectados por Trypanosoma cruzi, mostrando una elevada tasa de $7,3 \%(23 / 311)^{1}$. Schenone y col, en 1968, efectuaron una investigación en el banco de sangre del Hospital Clínico de la Universidad de Chile, detectando 2,97\% (15/505) de seropositivos para $\mathrm{T}$ cruzi $^{2}$. Posteriormente, se comunicaron diversos trabajos que permitieron configurar un detallado conocimiento epidemiológico, sobre la importancia de la enfermedad de Chagas transfusional en el país ${ }^{3-6}$. En 1981, Noziglia y col describieron tres casos de enfermedad de Chagas adquiridas por esta vía en Chile ${ }^{7}$.

La enfermedad de Chagas es una de las parasitosis para la cual la Organización Mundial de la Salud (OMS), a través de su programa TDR (Tropical Diseases Research) destina recursos para alcanzar su control ${ }^{8}$. En Chile, en el área del control de las infecciones parasitarias humanas, se han conseguido logros destacados como impedir la transmisión autóctona de la malaria en la región del extremo norte del país y declarar interrumpida la transmisión del agente causal de la enfermedad de Chagas mediante el insecto domiciliario Triatoma infestans ${ }^{9,10}$. La transmisión de la enfermedad de Chagas mediante transfusiones sanguíneas se controla a través del descarte de sangre que presente anticuerpos anti $\mathrm{T}$ cruzi, determinadas mediante pruebas de tamiz o screening. Estas se realizan rutinariamente en los bancos de sangre de la zona endémica de transmisión vectorial de la enfermedad de Chagas ${ }^{11}$. Escasos estudios sobre el estado actual de la transmisión por transfusiones sanguíneas de la enfermedad de Chagas han sido comunicados en Chile ${ }^{12}$.

El objetivo de nuestro trabajo es analizar y actualizar cifras de prevalencia de donantes de sangre con anticuerpos anti T cruzi entre los años 2000 y 2004 en el Hospital Clínico de la Universidad de Chile, así como la determinación de algunos parámetros parasitológicos y epidemiológicos de ellos.

\section{MATERIAL Y MÉTODO}

La investigación se efectuó en dos periodos: Parte A. En 1998 se estudiaron 75 donantes de sangre con anticuerpos anti T cruzi determinados mediante Enzyme Linked Immune System Assay (ELISA). Estos donantes fueron seleccionados aleatoriamente de los registros del banco de sangre, fueron visitados en sus domicilios para entrevista y extracción de sangre venosa, previo otorgamiento de consentimiento informado. La entrevista se efectuó para determinar parámetros epidemiológicos útiles, que se relacionaran positivamente con la existencia de la parasitosis en los donantes de sangre. Para esto se preguntó sobre el insecto vector y se solicitó responder afirmativa o negativamente a las siguientes preguntas: a) ¿Conoce la vinchuca? (nombre popular del Triatoma en Chile), b) iHa sido picado por una vinchuca?, c) ¿Su madre conoce la vinchuca?, d) ¿Su madre ha sido picada por una vinchuca? Esta misma entrevista se hizo a 78 donantes de sangre pareados por edad y que tenían una ELISA para T cruzi negativa. La muestra de sangre venosa extraída a los donantes que eran seropositivos para $\mathrm{T}$ cruzi mediante prueba tamiz en el banco de sangre, fue procesada en el laboratorio de Parasitología de la Facultad de Medicina de la Universidad de Chile, mediante las técnicas de hemoaglutinación indirecta y ELISA IgG para confirmar la presencia de anticuerpos anti $\mathrm{T}$ cruzi ${ }^{13}$. También se efectuó reacción en cadena de la polimerasa (PCR), que amplifica un segmento de $330 \mathrm{pb}$ de ADN del kinetoplasto de T cruzi $^{14}$. Finalmente, se efectuó a cada individuo seropositivo encuestado un xenodiagnóstico con dos cajitas que contenían ninfas de IV estadio de Triatoma infestans ${ }^{15}$ para determinar la presencia del $\mathrm{T}$ cruzi vivos en la sangre de los donantes y comparar el rendimiento de este método de diagnóstico frente al ensayo PCR. Parte B. Durante enero de 2000 y diciembre de 2004, se efectuó la prueba de ELISA para detectar anticuerpos anti T cruzi a un total de 30.309 donantes de sangre que concurrieron al banco de sangre del Hospital Clínico de la Universidad de Chile. Conjuntamente a la prueba de ELISA efectuada, se registró el domicilio informado por dichos donantes durante la entrevista.

Estadística. El estudio estadístico de la significancia de las diferencias observadas se efectuó mediante el estadígrafo Chi cuadrado de EPINFO 6.0. 


\section{RESUltados}

Un porcentaje mayor de donantes chagásicos respondieron que ellos o sus madres habían sido picados por una vinchuca y esta diferencia fue estadísticamente significativa, en ambos casos respectivamente: $28,0 \% \mathrm{v} / \mathrm{s} \quad 6,4 \%, \mathrm{p}<0,001 \mathrm{y}$ $22,7 \%$ v/s $8,9 \%, p<0,03 \%$.

PCR fue positiva en 52/75 (69,3\%); en tanto que el xenodiagnóstico lo fue sólo en 16/75 (21,3\%). Sin embargo, hubo cinco chagásicos con xenodiagnóstico positivo y la respectiva PCR negativa. El resultado contrario, es decir PCR positiva con xenodiagnóstico negativo se observó en 41 individuos.

En la Tabla 1 se muestra la frecuencia anual (2000-2004) de donantes de sangre con anticuerpos anti $\mathrm{T}$ cruzi positivos mediante ELISA. Se puede apreciar que los porcentajes variaron entre 0,31 y 0,45 , con un promedio de 0,4 . La diferencia entre la frecuencia observada en el año 2004 con la de los restantes, no fue estadísticamente significativa.

De los 125 donantes ELISA positivos para T cruzi, la mayoría comunicó que la Región Metropolitana era su lugar de residencia. Sin embargo, hubo también donantes que procedían de otras regiones del país, incluyendo uno que residía en la cuarta, dos en la quinta y uno en la octava.

Finalmente, en la Tabla 2 se comparan las frecuencias de individuos con anticuerpos anti $\mathrm{T}$ cruzi, comunicada en dos trabajos efectuados en el mismo centro hospitalario en los años 1968 y 1982 con la detectada en el presente estudio. Ha

Tabla 1. Frecuencia anual de detección de hemodonantes con anticuerpos anti $T$ cruzi en el H ospital Clínico de la Universidad de Chile. 2000-2004

\begin{tabular}{|lccc|}
\hline Año & Donantes & \multicolumn{2}{c|}{ Positivos } \\
& & № & $\%$ \\
\hline 2000 & 6.130 & 26 & 0,42 \\
2001 & 5.999 & 27 & 0,45 \\
2002 & 6.193 & 25 & 0,40 \\
2003 & 6.265 & 27 & 0,43 \\
2004 & 6.321 & 20 & 0,31 \\
Total & 30.908 & 125 & 0,40 \\
\hline
\end{tabular}

habido un notorio descenso, desde $2,97 \%$ a $0,31 \%$, $\mathrm{p}<0,01$.

\section{Discusión}

En Chile, en la zona endémica de transmisión vectorial domiciliaria por T infestans de la enfermedad de Chagas (I a VI regiones geopolíticas y la Región Metropolitana) existe una cobertura de $100 \%$ para el descarte de sangre que presenta anticuerpos anti $\mathrm{T}$ cruzi ${ }^{11}$. La implementación de este sistema permitió, específicamente en el Hospital Clínico de la Universidad de Chile, que entre los años 2000 y 2004, se eliminaran 125 bolsas de sangre por presentar anticuerpos anti T cruzi. La mayoría de estos donantes comunicaron que procedían de la Región Metropolitana o regiones aledañas a la zona endémica de transmisión vectorial por T infestans. Sólo hubo un donante que residía en la VIII región (zona no endémica). La presencia de donantes de sangre infectados por T cruzi en las regiones centro-sur del país, donde no se hace tamiz para detectar enfermedad de Chagas en los bancos de sangre, ya había sido constatada, encontrándose 14 positivos de 9.308 estudiados $(0,15 \%)$ en 13 hospitales localizados en dichas regiones. Nueve de estos donantes habían emigrado desde localidades rurales-periurbanas donde existia $\mathrm{T}$ infestans ${ }^{5}$. Por otra parte, en siete hospitales de la VII región se estudiaron 1.581 donantes, encontrándose uno positivo con anticuerpos anti $\mathrm{T}$ cruzi ${ }^{16}$. En los bancos de sangre de Chile localizados en área no endémica de

Tabla 2. Comparación de las frecuencias porcentuales de hemodonantes con anticuerpos anti T cruzi del H ospital Clínico de la Universidad de Chile en tres años durante el periodo 1968-2004

\begin{tabular}{|lccc|}
\hline Año & Donantes & \multicolumn{2}{c|}{ Positivos } \\
& & № & $\%$ \\
\hline 1968 & 505 & 15 & $2,97^{*}$ \\
1982 & 1.000 & 20 & $2,0^{\text {** }}$ \\
2004 & 6.321 & 20 & 0,31 \\
\hline
\end{tabular}

*Schenone y col${ }^{2} ;{ }^{* *}$ Contreras y col $^{5}$. 
transmisión vectorial por T infestans, la prevalencia de donantes positivos para $\mathrm{T}$ cruzi varía entre 0,6 y 1,5 por $1.000^{5,16}$, estimándose con esto una cifra de 1 por cada 1.000 para bancos de sangre de estas zonas ${ }^{17}$.

Se ha propuesto el uso de una entrevista predonación dirigida a descartar donantes de sangre infectados por T cruzi en estas regiones donde no se practica rutinariamente el tamiz serológico ${ }^{16}$. Dado que la población de Chile tiene algún grado de conocimiento de la enfermedad de Chagas y sus formas de transmisión, la pregunta: ¿Conoce las vinchucas?, no sería orientadora en la búsqueda de donantes infectados por T cruzi, como ya fuera constatado ${ }^{16}$. En este estudio, la pregunta: ¿Ha sido picado usted o su madre por una vinchuca? tuvo respuesta afirmativa sólo en cerca de $20 \%$ de los donantes chagásicos, valor similar al observado en un anterior estudio ${ }^{6}$.

El hecho que los donantes con anticuerpos anti $\mathrm{T}$ cruzi presentan parásitos vivos en su sangre fue demostrado por la aplicación del xenodiagnóstico, resultando positivo en $21,3 \%$ de los estudiados. Similar resultado de 17,6\% (19/108) se obtuvo en un trabajo previo ${ }^{5}$. Estos porcentajes son sensiblemente menores al de 50\% considerado para esta prueba en individuos crónicos con anticuerpos anti $\mathrm{T}$ cruzi ${ }^{15}$. Factores como parasitemia variable, susceptibilidad a la infección por $\mathrm{T}$ cruzi del artrópodo y cepa de T cruzi han sido sugeridos para explicar este fenómeno ${ }^{18}$. PCR se mostró de mayor sensibilidad que el xenodiagnós-

\section{REFERENCIAS}

1. Howard J, Rubio M, Knierim F, Garcia-Huidobro J. Investigación de la infección tripanosómica $(\mathrm{T}$ cruzi) en dadores del Banco de Sangre del Hospital Luis Calvo Mackenna. Bol Chil Parasitol 1962; 17: 29.

2. Schenone H, Rubinstein P, Knierim F, Sandoval J, Rojas A. Infección por Trypanosoma cruzi en dadores de sangre de un hospital de Santiago, Chile. Bol Chil Parasitol 1968; 23: 83-4.

3. Apt W, Pérez C, Sandoval J. Prevalencia de la infección chagásica en 4 bancos de sangre de diferentes zonas del país. Rev Méd Chile 1980; 108: $112-4$. tico, alcanzando $69,3 \%$ de positividad en los donantes de sangre. La sensibilidad de esta prueba es variable, describiéndose índices de 3,8\% hasta 100\% para chagásicos crónicos en diversos estudios realizados ${ }^{19}$. Bajo nuestras condiciones de trabajo, PCR mostró elevada sensibilidad aunque en cinco individuos cuyo xenodiagnóstico fue positivo resultó negativa. Esto demostraría la conveniencia de usar tanto xenodiagnóstico como PCR para evidenciar la presencia del parásito en la sangre de un paciente chagásico crónico.

Las cifras de prevalencia de individuos con anticuerpos anti T cruzi de 0,31\% determinada en este estudio, muestran un notable descenso cuando se compara con la descrita en el año 1968. Sin embargo, entre los años 2000 y 2004, se observó una mantención de la cifra de detección de individuos que varió entre 20 y 27 casos cada año. Se ha estimado que el riesgo de infección de un receptor de sangre por una transfusión proveniente de un donante chagásico es de $20 \%{ }^{17}$. Aplicada esta cifra a $60 \%$ del universo de donantes positivos detectados en el banco de sangre del Hospital José Joaquín Aguirre (para excluir posibles resultados falsos positivos en el tamiz serológico ${ }^{6}$ ), teóricamente se habría evitado la infección por este mecanismo de a lo menos 15 receptores entre los años 2000 y 2004. Los resultados obtenidos en este banco de sangre, muestran que la posibilidad de adquirir la enfermedad de Chagas por vía transfusional se ha reducido, manteniéndose el riesgo estable en años recientes.

4. Lorca M, Lorca J, Child R, Atias A, Canales M, LoRCA E, GutIÉRREZ J. Prevalencia de infección por Trypanosoma cruzi en pacientes politransfundidos. Rev Méd Chile 1988; 116: 112-6.

5. Contreras MC, Schenone H, Borgoño JM, Salinas $P$, Sandoval L, Rojas A, Solís F. Infección chagásica en donantes de sangre de hospitales de las regiones endémicas de Chile (1982-1987). Trascendencia epidemiológica del problema. Bol Chil Parasitol 1992; 47: 10-5.

6. García A, Celis D, León M, León P, Macchiavelo N, Miranda JP ET AL. Estudio clínico y epidemiológico de donantes de sangre seropositivos para la enfermedad de Chagas. Rev Méd Chile 1997; 125: 905-10. 
7. Nozigla C, Contreras J, Subercaseauz B, Joyas A. Enfermedad de Chagas post-transfusional. Rev Chil Pediatr 1981; 52: 318-22.

8. TDR 2005. 17th Programme Report. Making health research work for poor people.TDR/GEN/05.1. WHO.

9. Schenone H, Olea A, Rojas A, García N. Malaria en Chile: 1913-2001. Rev Méd Chile 2002; 130: 11706.

10. Moncayo A. Chagas disease: Current epidemiological trends after the interruption of vectorial and transfutional transmission in the southern cone countries. Mem Inst Oswaldo Cruz 2003; 98: 57791.

11. Informe de la Comisión de Certificación, Programa Nacional de Control de la Enfermedad de Chagas, Ministerio de Salud de Chile, Santiago, Chile,1999.

12. Schmunis GA, CRUZ JR. Safety of the blood supply in Latin America. Clin Microbiol Rev 2005; 18: 1229.

13. Contreras MC, Salinas P, Sandoval L, Solís F, Rojas A. Utilidad de la ELISA IgG en muestras de suero y fluidos de sangre en papel filtro en el inmunodiagnóstico de la enfermedad de Chagas. Bol Chil Parasitol 1992; 47: 76-81.

14. Vargas D, Wallace A, Solari A. Estandarización de la reacción de polimerización en cadena (PCR) en muestras de sangre de ratones infectados por Trypanosoma cruzi. Parasitol al Día 1996; 29: 136-40.

15. Schenone H, Rojas A, Mercado R, CastiLo D. Estudio comparativo de la sensibilidad y mortalidad de ninfas III y IV de Triatoma infestans usada en el xenodiagnóstico de pacientes chagásicos crónicos. Bol Chil Parasitol 2000; 55: 14-7.

16. Vásquez M, Vidal S, Espinoza C, Palomo I, Torres M, Alvarado C et al. Utilidad de una encuesta para identificar donantes de sangre de zonas no endémicas, potencialmente infectados por Trypanosoma cruzi. Parasitol al Día 1999; 23: 125-9.

17. Schmuniz GA, Zicker F, CRuz JR, Cuchi P. Safety of blood supply for infectious diseases in Latin American countries, 1994-1997. Am J Trop Med Hyg 2001; 65: 924-30.

18. Alves Martins LP, Aristeu Da Rosa J, Pires Castanho RE, Lopes Sautini G, Medeiros Junior H. Susceptibilidade de Rhodnius prolixus, Rhodnius robustus e Triatoma infestans a infecçao por duas cepas de Trypanosoma cruzi utilizando xenodiagnóstico artificial. Rev Soc Bras Med Trop 2000; 33: 55963.

19. Portela-Lindoso AA, Shikanai-Yasuda MA. Chronic Chagas'disease: from xenodiagnosis and hemoculture to polymerase chain reaction. Rev Saude Publica 2003; 37: 107-15. 